\title{
LA IDEOLOGÍA COMO "FILOSOFÍA PRIMERA" Y LA CLASIFICACIÓN DE LAS CIENCIAS EN DESTUTT DE TRACY
}

\author{
Ángei J. Cappelletti \\ Sociedad Venezolana de Filosofis
}

Antonio Destutt de Tracy, a quien Picavet ubica, junto con Pedro Cabanis, en la segunda generación de ideólogos (en la primera pone a Volney, Sièyes, Laplace, Condorcet), es tal vez el continuador más fiel de Condillac, aunque rechace expresamente varias de sus tesis. Mientras Cabanis parece sustituir en ocasiones el sensualismo cauto y minucioso del Traité des sensations (publicado el mismo año de su nacimiento) por el sensualismo audaz, transmutado ya sin rubor en materialismo, de L'homme machine, Destu't de Tracy prefiere elaborar una filosofía primera concebida como análisis de las facultades del alma. En sus Rapports du physique et du moral de l'homme (1802), sostiene Cabanis, sin ambages, que el cerebro es el órgano que produce el pensamiento del mismo modo que el hígado produce la bilis. Esta expresión (o una muy parecida) será utilizada por $\mathrm{H}$. Taine (a quien Picavet sitúa en la última generación de los ideólogos) en su célebre Historia de la literatura inglesa. De tal modo, Cabanis "acentúa - como dice R. Lefèvre- el papel de las condiciones fisiológicas y de las sensaciones internas, como fuente del pensamiento, del sueño y de la locura" (Condillac, p. 81), mientras Destutt de Tracy prefiere mantenerse en la línea del análisis psicoló gico, para derivar de él tanto la teoría del lenguaje (gramática), como la teoría del juicio (lógica) y la teoría de la voluntad (moral). No por nada la ideología, así comprendida, constituye, para él, la teoría de las teorías (Cfr. Riverso, I problemi della conoscenza e del metodo nel sensismo degli ideologi, 1962.)

Esta "teorfa de las teorfas" viene a ser, sin duda, una teoría del conocimiento, y desde tal punto de vista, puede decirse que Destutt de Tracy, con su análisis de las facultades cumple una tarea paralela a la de Kant (a cuya obra dedica una disertación publicada en 1802 en $M \dot{e}$. moires de l'Institut).

Pero, por otra parte, como sensualista y empirista, sólo puede entender la teoría del conocimiento como psicología del conocimiento, mientras 
Kant la interpreta como critica trascendental, esto es, como estudio de las condiciones de posibilidad del conocimiento.

Destutt de Tracy, básicamente antiescolástico y antirracionalista, considera, como Locke y Condillac, que antes de abordar el estudio de la realidad y del ser es indispensable averiguar cómo se conoce, cuál es el origen y cuáles los límites y las modalidades del conocimiento humano. Por eso antepone la gnoseología a toda suerte de ontología y de metafísica. La gnoseología resulta, para él, la filosofía primera. Pero tal gnoseología, al ser teoría de las teorías y filosofía primera, no puede recibir el nombre de "metafísica", porque, según él, esa palabra "designa una ciencia que trata de la naturaleza de los seres, de los espiritus, de los diferentes órdenes de inteligencia, del origen de las cosas, de sus causas primeras" (Mémoire sur la faculté de penser. "Mémoires de l'Institut National", 1798, T. I, p. 322, cit., por Gouhier). La palabra había sido utilizada todavía en 1793, por otro ideólogo, Laromiguière, pero no satisface, en general, a los filósofos de la Ilustración ni a sus inmediatos continuadores, los ideólogos.

Para Destutt tampoco sirve el término "psicologia", al que algunas veces -según él mismo advierte-, parecía inclinarse el propio Condillac. Dicho término parece suponer un conocimiento del ser (esto es, de la esencia) del alma, conocimiento que no poseemos, y, por otra parte, sugiere una investigación de las causas primeras, cuando lo que pretendemos es sólo conocer los efectos y las consecuencias de su actividad.

Cabría, sin duda, dar a la filosofía primera la denominación de "análisis de las sensaciones y de las ideas", pero, aparte de que esto serfa una perífrasis, designaría más bien la labor a cumplir, que la ciencia resultante de esa labor.

Destutt de Tracy propone, pues, que se la llame "ideología" o ciencia de las ideas. $Y$ es, como dice Gouhier, el primero que utiliza esta palabra, por él inventada, a la cual le encuentra muchas ventajas: 1) Es muy prudente (très sage), porque no supone nada dudoso o desconocido ni evoca ninguna idea de causa; 2) Tiene un sentido muy claro para todo el mundo; 3) Resulta rigurosamente exacta, esto es, adecuada a lo que quiere significar, pues quiere decir al pie de la letra: "ciencia de las ideas"; 4) También es exacta si se tiene en cuenta su etimología, ya que zíos o عió́a significa en griego "percepción visual" y, generalizando, "percepción" sin más; 5) De acuerdo con lo anterior, si se denomina "ideologia" a la ciencia que resulta del análisis de las sensaciones, se indican al mismo tiempo el fin y el medio.

La "ideología", asf entendida, no aspira a conocer al hombre sino en la medida en que tal conocimiento puede lograrse a través del análisis de sus facultades, y renuncia de antemano a todo cuanto tal análisis no 
puede revelarle. La filosofía primera queda así reducida a una ciencia emṕrica; más aún, a una ciencia natural y a una rama de la biologí. Es una parte de la zoología, aunque ella sea importante sobre todo en el hombre. Pero es, al mismo tiempo, la menos estudiada de todas las ciencias. Este hecho tiene, para el conde de Tracy, una explicación que a su vez no revela el origen de todas las técnicas y las ciencias. El hombre tiende siempre, por naturaleza, a solucionar primero los problemas más inmediatos y urgentes. Se cuida primero de satisfacer sus necesidades, después de conseguir sus placeres. Sólo más tarde se libra al conocimiento puro. Al final, una reflexión radical lo lleva a la filosofía. Puede decirse, entonces, que Destutt reconoce en el desarrollo del conocimiento humano cuatro etapas lógicas que son a la vez etapas históricas: 1) Artes (o técnicas) que tienden a satisfacer las necesidades humanas, a) socio-económicas (agricultura, medicina, etcétera); b) politicas (arte de la guerra, política práctica, etcétera); 2) Artes que tienden a procurar placer (poesia, bellas artes, etcétera); 3) Ciencias que surgen de la reflexión, a) sobre los juicios (lógica); b) sobre el lenguaje (gramática); c) sobre los deseos (moral); y 4) Filosofía primera o ideología, que trata de la fuente común del juicio, el lenguaje y el deseo, y del centro único de todas las verdades, mediante el análisis de las facultades intelectuales del hombre.

Esta filosofía primera es históricamente la última en aparecer y lógicamente el resultado postrero de la actividad intelectual. Surge mucho más tarde que todas las otras artes y ciencias. Al sostener esta tesis Destutt concuerda, en general, con Aristóteles y con cuantos en el pasado señalaron que el ave de Minerva no aparece sino en el crepúsculo. Sin embargo, su concepto de la filosofía primera difiere mucho del que define Aristóteles o sus seguidores antiguos y medievales. Deriva, como el propio conde de Tracy lo reconoce, de Locke y de Condillac. En el Prefacio de su obra capital Eléments d'Ideologie (Paris, 1970, p. XV-XVI), escribe: "Locke es, creo, el primero de los hombres que intentó observar y describir la inteligencia humana como se observa y describe una propiedad de un mineral o de un vegetal, o de una circunstancia notable de la vida de un animal, con lo cual ha hecho de ese estudio una parte de la Ffsica. No es que antes que él no se hayan propuesto muchas hipótesis sobre el tema y que inclusive no se haya dogmatizado con gran osadía sobre la naturaleza de nuestra alma, pero esto no tenía por objeto descubrir la fuente de nuestros conocimientos, su certeza y sus límites, sino determinar el principio y el fin de todas las cosas y adivinar el origen y el destino del mundo. Ése es el objeto de la Metaffisica. La colocaremos entre las artes de imaginación destinadas a satisfacernos y no a instruirnos." Es evidente que la filosoffa primera de Destutt de Tracy se remite ante todo al Ensayo sobre el entendimiento humano, publicado más de 
un siglo antes, en 1690, por John Locke. En la Epistola al lector que antepone a dicha obra, refiere éste que, reunido en cierta ocasión con cinco o seis amigos, había emprendido con ellos una discusión (tal vez un tema teológico o metafísico) y que, al no poder llegar a conclusión alguna, se le ocurrió la idea de que había tomado un camino equivocado (it came into my thoughts that we took a wrong course) y era necesario examinar antes las propias capacidades y ver qué objetos estaban o no estaban al alcance del conocimiento humano (it was necesary to examine our own abilities, and see what objects our understandings were or where not fitted to deal with). La idea del análisis del entendimiento como ciencia previa, o sea, como filosofía primera, resulta así claramente expresada por Locke, aunque él no le atribuya una denominación especial. Más aún, el propósito que Destutt de Tracy enuncia en el párrafo antes citado de sus Éléments d'Ideologie es también expresamente formulado por Locke en la Introducción a su Essay Concerning Human Understanding (2): "investigar el origen, la certeza y la extension del conocimiento humano" (to inquire into the original, certainty and extent of human knowledge). Resulta también bastante claro que el tipo de especulación sobre el conocimiento y el alma que Destutt rechaza es el de Aristóteles (cuyos tratados De anima y De sensu contienen, sin embargo, muchos más elementos de observación y análisis de los que Destutt supone), pero también el de Descartes, Malebranche, Spinoza y los racionalistas del siglo xvir en general, tan duramente combatidos por el propio Locke y por Condillac. Es curioso, de todas maneras, que el ideólogo francés en vez de excluir como algo absolutamente inservible la metafísica (tal como harán luego algunos positivistas), le atribuya cierta dignidad estética y se incline a ubicarla entre las artes que tienden a procurar placer (tal como suelen hacerlo también en nuestros días aquellos críticos que hablan de ella como de una especie de "poesía de ideas").

Aun cuando Destutt de Tracy reconoce que Locke fue el iniciador de la observación y el análisis empírico del entendimiento como tarea previa a toda otra ciencia o filosofia, explícitamente atribuye a Condillac la creación de la ideología. Entre los buenos ingenios que siguieron a Locke, aquél "aumentó más que ninguno el número de sus observaciones", con lo cual fundó realmente la filosofía primera, en el sentido que, según Destutt, debe entenderse tal disciplina.

Sin embargo, éste dista bastante de darle al famoso abate un consentimiento total: "A pesar de la excelencia de su método y de la seguridad de su juicio - dice- no parece haber estado exento de errores". La razón de tales errores la encuentra en el hecho de que "nuestras percepciones puramente intelectuales son muy fugitivas y cuanto menos 
el objeto de nuestras investigaciones nos reconduce con frecuencia al testimonio directo de nuestros sentidos, más sujetos estamos a engañarnos y perdernos". La explicación responde, sin duda, perfectamente al común sensualismo de Condillac y del propio Destutt; en cambio, lo que resulta sorprendente y extraño es que éste considere que las obras teóricas de aquél "no son casi más que fragmentos desgajados de los monumentos de sus investigaciones" (ne sont presque que des morceaux détachés des monuments de ses recherches). Según Destutt, Condillac "se dedicó a aplicar sus descubrimientos a las artes de hablar, de razonar, de enseñar, pero no se ocupó de reunirlos y no nos ha dado en ninguna parte un cuerpo de doctrina completo que pudiera servir de texto a las lecciones de un curso." Sin duda, el arte de hablar corresponde a la Gramática, que forma parte del Curso de estudios para la instrucción del principe de Parma; el arte de razonar es desarrollado en La logica o los primeros desarrollos del arte de pensar; y el arte de enseñar se encuentra aplicado en todo el Curso de estudios y teóricamente explicado (como didáctica y metodologia) en el Discurso preliminar de esa misma obra. Pero dacaso las dos más importantes y conocidas obras de Condillac, el Ensayo sobre el origen de los conocimientos humanos (1746) y el Tratado de las sensaciones (1754), no deben considerarse como dos intentos sucesivos de sistematizar esta "filosofía primera", como escrupuloso examen del origen y desarrollo del conocimiento humano, es decir, como "Ideologia" o "ciencia de las ideas"? Lo que Destutt echa de menos en Condillac es posiblemente la sistematización didáctica que él intenta dar de la ideología, y la conexión pedagógica de la misma con las otras partes de la filosofía del sujeto, esto es, con la lógica, la gramática y la moral. Esta conexión queda establecida en sus propios Éléments d'Idéologie, publicados en París por Courcier, cuyo primer tomo, aparecido en 1803, está dedicado a la Idéologie proprement dite, mientras que el segundo de aquel mismo año se intitula Gramaire, el tercero, de 1805, Logique, y el cuarto, de 1815, Traité de la volonté et de ses effets (esto es, Moral).

Por otra parte, como bien hace notar Gouhier, la ideologia es, para Destutt de Tracy, "una ciencia que, como las de la naturaleza, demuestra su eficacia en lo que llamamos ciencias aplicadas", por lo que al mismo tiempo que escribe su gran obra, publica tres libritos que ilustran los propósitos de su filosofía: 1) Quels son les moyens de fonder la morale chez un peuple? (1798), donde sostiene que la moral consiste en el estudio de nuestras tendencias y sentimientos en tanto influyen en nuestra felicidad, por lo cual no puede ser otra cosa más que una aplicación de la ciencia que estudia la generación de tales tendencias y sentimientos; 2) Abregé de "L'Origine de touts las cultes" par le citoyen Dupuis 
(1799): donde vincula la ideología con la lucha contra la superstición y la religión positiva en general y expone en resumen las teorías naturalistas de Dupuis acerca del origen de todas las religiones y en especial del cristianismo; 3) Observations sur le système actuel d'instruction publique (1800), donde propone una reforma de las escuelas y universidades nacionales, partiendo de sus propias ideas sobre el conocimiento y sobre las ciencias teóricas y aplicadas. Más adelante publicará también otras dos obras en las que la ideologia se aplica al estudio de la politica, el derecho, y la historia; Commentaire sur "l'Espirit des lois" (1819) y de la economía: Traité d'economie politique (1822).

Por otra parte, en la edición de sus Eléments d'Ideologie del año 1824 antepone Destutt un Cuadro y una Nota donde ubica las ciencias desarrolladas en la obra como parte de un conjunto más amplio y propone una clasificación de todas las ciencias que puede considerarse definitiva en su pensamiento. Alli, el sistema de las ciencias, cuya base es la ideologia, recibe como siempre también el nombre genérico de ideologia (y también de "filosofía primera", lo cual resulta más extraño) y comprende tres secciones integradas cada una por tres ciencias: I) Ciencias que estudian genéricamente ("histoire") los medios de conocimiento, que son: 1. Ideologia propiamente dicha, que trata de la formación de las ideas (y construye, en sentido propio, la filosofía primera o ciencia fundamental); 2. Gramática, que trata de la expresión de las ideas; 3. Lógica, que se ocupa de la combinación de las ideas; II) Ciencias que aplican los medios de conocimiento (estudiados en las ciencias antes nombradas) al estudio de la voluntad y de los efectos de la misma: l. Economia, que versa sobre las acciones; 2. Moral, que versa sobre los sentimientos; 3, Legislación, que versa sobre la dirección de acciones y sentimientos; III) Ciencias que aplican los medios de conocimiento al estudio de los seres distintos del hombre: 1. Fisica, que estudia los cuerpos y sus propiedades; 2. Geometria, que estudia las propiedades de la extensión; 3. Cálculo, que estudia las propiedades de la cantidad. A estas nueve ciencias considera necesario añadir una disciplina crítica o ciencia de la superstición y del sofisma, la cual tiene por objeto "las falsas ciencias que aniquilan el conocimiento de nuestros medios de conocer y su legítimo empleo". (Aristóteles concluye su Organon con las Refutaciones sofísticas.)

En la Nota que sigue al esquema clasificatorio Destutt aclara: "Cuando este cuadro sea llenado, pienso firmemente que se tendrán por fin los verdaderos elementos de la Ideologia, si se quiere, Filosofía primera, o, en otros términos, un Tratado completo del origen de nuestros conocimientos." Es claro que fuera de este cuadro quedan las ciencias aplicadas propiamente tales, es decir, las diferentes técnicas (medicina, agro- 
nomía, etcétera). Este último grupo de ciencias al cual Destutt no concede un lugar allí, porque no las considera parte de la Ideologia (en sentido genérico), es el que Aristóteles habría denominado "ciencias poéticas o del hacer"; las que él llamaba en cambio "ciencias prácticas o del obrar", corresponden al segundo grupo y la segunda sección en la clasificación de Destutt, mientras las denominadas por el estagirita "ciencias teóricas" corresponden al tercer grupo (Física, Matemáticas) pero abarcan también parcialmente al primero, en la medida en que la Ideología es la Filosofía primera. A pesar de que la teoría aristotélica insiste en señalar la sensación como inicio de toda clase de conocimientos (nihil est in intellectu quod prius non fuerit in sensu). Tesis no desdeñable para un sensualista como Destutt (penser c'est sentir, si les mots de notre langue étaient bien faits du bien appliquées, nous devions apeller cette faculté sensibilité et ses productions Sensation ou sentiments). No parece que la clasificación aristotélico-escolástica de las ciencias haya sido tenida en cuenta por Destutt. En cambio, su clasificación podría reducirse (en lo que toca a sus grandes secciones) a la admitida por los estoicos y los epicúreos. La primera sección de Destutt corresponde sin duda a la Lógica de los primeros y a la Canónica de los segundos; la segunda sección coincide con lo que unos y otros llaman Moral; y la tercera, con lo que ambas escuelas denominan genéricamente Física. Si tenemos en cuenta el prestigio que el estoicismo y, en muchos casos el epicureismo, adquieren en ei medio intelectual de la Ilustración, parece probable que la antigua clasificación de las ciencias haya influido (consciente $o$ inconscientemente) sobre la del conde de Tracy. Es cierto que la de Francis Bacon, divulgada por D'Alembert, también parece haber sido tenida en cuenta por él en cuanto vincula cada ciencia con la facultad del alma que la origina. En cambio, la clasificación de Destutt de Tracy no ha tenido, al parecer, ninguna influencia en la de Auguste Comte (con su progresión lógica desde la máxima extensión y mínima comprensión hasta la máxima comprensión y mínima extensión) ni en la de Herbert Spencer (ciencias abstractas, concretas, abstracto-concretas). Nada tienen que ver con ella, desde luego, los intentos de Windelband por establecer una clasificación basada en las diferencias metodológicas (ciencias ideológicas y nomotéticas). En cambio, la elaboración de las ciencias de las ideas como ciencia básica de Destutt no deja de encontrar un eco (por más remoto que sea) en el proyecto de Dilthey de elaborar una psicologia como fundamento de todas las ciencias del Espíritu.

En efecto, la filosofía primera o Ideología de Destutt de Tracy, que es, ante todo, como lo demuestran las cuatro partes de los Eléments, fundamento de las ciencias del sujeto (esto es del espíritu), podria consi- 
derarse, según el propio filósofo ha advertido refiriéndose a su maestro Condillac, como una psicologia. Se trata, sin embargo, de una psicologia que, por oposición a la postulada por Dilthey, pretende ser una ciencia de la naturaleza, una parte de la física o, más especfficamente, de la zoología. Sin embargo, esta ciencia se limita para él a la descripción y una de las cosas que le reprocha a Condillac es el haber pretendido dar una explicación de los hechos de conciencia. Todo esto no impide que Destutt pueda también considerar su ideologia como origen de las ciencias ajenas al sujeto (física, matemáticas), con lo cual, de alguna manera, justifica la posterior idea diltheyana de que las ciencias de la naturaleza también forman parte de las ciencias del espíritu, en tanto son productos de la actividad espiritual del hombre.

Destutt de Tracy parte del pensar como un hecho inmediatamente dado en la conciencia (une verité d'expérience). $\mathrm{Y}$ la primera pregunta que se hace, pregunta tan fundamental como insólita (la mayoría de los hombres mueren sin habérsela formulado nunca), es la siguiente: ¿Qué significa pensar? (Quest-ce que penser?). Apelando a la experiencia más inmediata y al análisis del lenguaje común, comprueba que la expresión "yo pienso" (je pense) se aplica: 1) al juicio, por el cual siento que existe una relación entre dos cosas; 2) al recuerdo o la memoria, por la cual siento una cosa del pasado; 3) al deseo o la voluntad por la cual siento que quiero una cosa; 4) a la sensación por la cual siento algo actual y presente, que no es el recuerdo de una cosa pasada, ni una relación existente entre las ideas, ni un deseo de poseer o de evitar un objeto cualquiera. Las tres primeras modalidades del yo pienso, esto es, el juicio, la memoria y la voluntad, se reducen a la cuarta, esto es, a la sensación, ya que en todas ellas siento algo. "Pensar, como veis, - dice Destutt- es siempre sentir algo y no es nada más que "sentir". El sensualismo desarrollado por Condillac es así plenamente asumido en el comienzo mismo de la ideología o ciencia de las ideas.

La cuestión es ahora: ¿Qué significa sentir? Destutt no pretende, como Aristóteles o como los racionalistas, definir la sensación. La misma se nos hace evidente en la experiencia inmediata. Sentir - dice- es lo que experimentáis, y si no lo experimentarais( inútiles serfan todos mis esfuerzos por haceros saber en qué consiste. "Pero, puesto que tenéis conciencia de tal manera de ser - añade - no tenéis necesidad de explicación alguna para conocerla: vuestra experiencia os basta." Puede decirse, sin embargo, que Destutt llega al fondo del asunto cuando identifica el sentir con nuestra propia existencia: "Sentir es un fenómeno de nuestra existencia, es nuestra existencia misma" (sentir est un phénomène de notre existence, c'est notre existence elle-même). La equivalencia de ideologia y ontologfa resulta así patente, ya que, para Destutt, comenzar 
por la sensación no es otra cosa que comenzar por la existencia del ser. Pero se trata del ser del sujeto y, en tal sentido, la identificación entre ser y pensar o entre existir y sentir (que no implica siquiera un entimema como el del "cogito" cartesiano), comporta un punto de partida tan idealista como el de Descartes, que bien podría conducir a Destutt a un acosmismo semejante al de Berkeley, lo cual se opone evidentemente al propósito enunciado ya en el Prefacio de los Eléments de estudiar las facultades del alma humana como parte de la zoología. En efecto, si sentir es lo mismo que existir, ello se debe al hecho de que "un ser que no siente nada puede existir para los otros seres, si éstos lo sienten, pero no existe por sí mismo, puesto que no se da cuenta de ello". "Existir" supone, pues, en todo caso, "ser sentido" (Esse est percipii), ya sea por el mismo sujeto, ya por otros, y lo que no se siente a si mismo ni es sentido por otros simplemente no tiene existencia. Ya Diderot, en su Lettre sur les aveugles (1749), había advertido que el idealismo difícilmente podria ser refutado a partir de los principios de Condillac, idénticos a los de Berkeley. Condillac se esforzó, por eso, en su Traité des sensations (1754), por romper el círculo de la inmanencia y por sacar al sujeto de sí mismo. El medio que encuentra para ello es la actividad del tacto, el cual, a diferencia de los otros sentidos, por la sensación de resistencia que ofrece al sujeto, hace que éste salga de sí mismo y llegue al objeto. En el capítulo IX de su Ideologie, Destutt afronta el mismo problema que su antecesor Condillac, pero le da una solución un tanto diferente. Para él, la capacidad de resistir a nuestra voluntad está en la base de todo nuestro conocimiento del mundo, pero sólo llegamos a descubrir tal capacidad por medio de nuestros movimientos, efectos de nuestra voluntad. Dicha capacidad es la fuerza de inercia de los cuerpos, que no se descubre sino por el hecho de que éstos se muevan. Si la materia fuera completamente inmóvil, nada sentiriamos $y$, aun cuando algo sintiéramos, nada harfamos y sólo conoceriamos nuestras propias sensaciones. Si, por el contrario, ella fuera completamente móvil y carente de resistencia, nada sentirfamos, ya que todas nuestras sensaciones son producto de la resistencia de nuestros órganos a la acción de los cuerpos y de la resistencia de cada cuerpo a la acción de los demás, y si pudiéramos sentir y obrar, lo haríamos sin advertirlo, de modo que nunca descubriríamos la existencia de los cuerpos ni de nuestros propios órganos. Pero, cuando podemos obrar y darnos cuenta de ello, querer y experimentar resistencia, el universo -esto es, la realidad objetiva-, nace para nosotros. Cabanis, médico-filósofo a quien Destutt de Tracy conoce en Auteuil, en casa de la señora Helvetius, y con el cual comparte muchas ideas filosóficas y políticas, defiende la misma tesis: sólo llegamos a conocer los cuerpos por la sensación de resistencia que ellos 
nos proporcionan, la cual se manifiesta en la percepción del movimiento y en la voluntad que impulsa a éste, de modo que la noción de un yo (sujeto) diferente de las cosas (objetos) no se conquista sino por medio de la conciencia del esfuerzo y del acto de voluntad (Rapport du physique et du moral de l'homme, Oeuvres, París, 1956, p. 546). La tesis será retomada y modificada, en un contexto ajeno ya al sensualismo de Destutt y Cabanis, por Maine de Biran y, finalmente, por Dilthey. Para Destutt de Tracy se justifican así la física y las ciencias de la naturaleza, pero sin duda la gramática también, pues los signos y el lenguaje carecerian de sentido si no hubiera otros sujetos distintos del propio yo, cuya existencia sólo puede ser conocida a través de la existencia de los respectivos cuerpos (aunque "con signos no inequívocos"), lo mismo puede decirse de la moral y aun de la lógica. En todo caso, parece contradictorio o por lo menos, metodológicamente inaceptable, que al tratar de las sensaciones (Cap. II), Destutt dé por supuesta la existencia objetiva del propio cuerpo y de los cuerpos ajenos. Allí sostiene, en efecto, que la sensibilidad se encuentra en las diferentes especies de animales y que, aun cuando no se manifiesta del mismo modo en los vegetales, nadie podría asegurar que no existe en ellos o inclusive en los minerales. Alli mismo dice que "en buena filosofía es preciso no suponer nunca nada". Pero es claro que en todo esto está "suponiendo" que existen animales, vegetales y minerales fuera del pensamiento y de la sensibilidad, lo cual de ninguna manera se ha demostrado todavia. Ni siquiera se ha demostrado que más allá del pensamiento exista un cuerpo que lo sustente, ni siquiera se ha probado que, aparte del alma, haya un cuerpo humano. $Y$, sin embargo, Destutt no duda en afirmar que sabemos por medio de cuáles órganos opera nuestra sensibilidad y en hablar de los nervios, considerándolos vehículos principales de la misma y describiéndolos como "hilitos de una substancia blanda, de la misma naturaleza más o menos que la pulpa cerebral", que parten del cerebro y en él se reúnen y confunden y que desde él, por una multitud de ramificaciones y subdivisiones, se extienden al infinito y llegan a todas partes del cuerpo humano. Desde este punto de vista, Destutt representa un retroceso con respecto a Condillac en cuyo Traité des sensations, la Primera parte trata de los sentidos que por sí mismos no suponen la existencia de objetos exteriores al sujeto pensante o sensiente, y no menciona en absoluto ni los cuerpos ajenos (animales, plantas, minerales) ni el propio cuerpo del sujeto, mientras la Segunda parte se refiere al tacto, único sentido que por sí mismo alcanza los objetos exteriores, y recién en la Tercera parte se investiga cómo el tacto enseña a los otros sentidos a conocer los objetos exteriores.

Un empirismo radical, como el de Berkeley y el de Condillac (que 
Destutt acepta), se ve siempre enfrentado al dilema idealismo subjetivomaterialismo filosófico y, en última instancia, se ve obligado a optar entre la disolución del mundo (acosmismo, fenomenismo, etcétera) y la disolución del yo (fisiologismo, reduccionismo, etcétera). Tanto Condillac como Destutt de Tracy intentan evitar ambos extremos, pero aunque ninguno de los dos quisiera desembocar en un materialismo como el de Lamettrie o el Barón de Helvetius - aunque ninguno de ellos llega a inclinarse tan abiertamente como Cabanis o Broussais hacia una interpretación fisiologista del proceso cognoscitivo-, es claro que, ajenos al kantismo y a la filosofía idealista alemana, impresionados por los progresos de la física, de la química y de la biología, todo los lleva a marchar más en esa dirección que en la contraria. La influencia de Kant y de Hegel originará en Francia, a partir de aquí, el eclecticismo espiritualista de Cousin, pero el destino de la ideología, si se tienen en cuenta las tendencias predominantes en la Francia del siglo xIx, es la psicofisiologia de Taine, filosofía primera y fundamento de todos sus' estudios históricos, literarios, sociológicos, estéticos, etcétera. (Cfr. P. Lacombe, La psychologie des individus et des societés selon Taine, París, 1906; A. Chevillon, Taine, Formation de sa pensée, París, 1928). La Ideologie del conde de Tracy desemboca en el De l'intelligence de Hipólito Taine.

De hecho, Destutt de Tracy reconoce la existencia de dos ideologias, una fisiológica y otra racional, aunque sabe muy bien que la primera supone un cúmulo de conocimientos que, en su época, están lejos de haberse alcanzado. Esto no impide que su amigo Cabanis intente ya desarrollarla. Destutt, más prudente, aunque deplora no haber podido referir a la fisiología su ideología, permanece en el campo de la observación. Como dice Rivaud, "lo que Tracy acaba de esbozar es una psicologfa más o menos conforme al modelo creado por Condillac, según Locke", y aunque la misma muestra tendencias francamente materialistas, aquél se guarda, en principio, de las fórmulas agresivas familiares a sus inspiradores ( $\mathrm{y}$ también podría añadirse que a sus contemporáneos, como Cabanis, y a sus continuadores, como Taine). Tracy pretende basarse sólo en la observación y en los datos de los sentidos y, en teoria, las informaciones procedentes de la conciencia para él ocupan el sitio principal, aunque las mismas — según el citado historiador de la filosofía-, tengan poca influencia en las conclusiones, y la experiencia interior no desempeñe sino un papel secundario. "Razona siempre sobre definiciones abstractas y sobre una clasificación a priori de las facultades. Según confiesa él mismo, recurre muy poco a la fisiología. La ideología es un juego ingenioso sobre abstracciones", dice Rivaud (Histoire de la philosophie, Paris, 1962, IV, p. 408). Habría que ver, sin embargo, hasta qué punto estas "definiciones abstractas" no son más bien resul- 
tado de un análisis del lenguaje como sistema de signos de la experiencia y del pensamiento. En todo caso, no puede olvidarse, como se encarga de advertir el mismo Rivaud, que "análisis lógicos muy cercanos a los de Tracy figuran en Taine, Ribot, P. Janet, Wundt y el mismo Freud", y que a tales análisis "sólo se les ha yuxtapuesto un conocimiento del sistema nervioso más preciso, si bien muy imperfecto". 